\title{
ANALISIS VARIASI WAKTU KEBERANGKATAN KENDARAAN DAN ARUS JENUH DASAR PADA SIMPANG BERSINYAL DENGAN METODE TIME SLICE (STUDI KASUS : SIMPANG BERSINYAL DI RUAS JALAN KAPTEN MULYADI, SOLO)
}

\author{
Ahmad Fauzi Arief ${ }^{1}$ ), Amirotul M.H.M. ${ }^{2}$ ), Slamet J. Legowo ${ }^{3}$ ) \\ 1) Mahasiswa Fakultas Teknik, Prodi Teknik Sipil, Universitas Sebelas Maret \\ 2) Pengajar Fakultas Teknik, Prodi Teknik Sipil, Universitas Sebelas Maret \\ 3) Pengajar Fakultas Teknik, Prodi Teknik Sipil, Universitas Sebelas Maret \\ Jl. Ir. Sutami 36A, Kentingan Surakarta 57126; Telp. (0271) 634524, Fax 662118 \\ Email : ahmadfauziarief10@gmail.com
}

\begin{abstract}
Captain Mulyadi road is one of the primary collector roads in Solo. In addition to being one of the connecting lanes for the entry and exit of vehicles from Sukoharjo and Wonogiri to Solo, along this section of the road is also a trading area, so that at certain times the condition of this road is quite dense. The increasing number of vehicle users also affects the higher traffic flow and also the conflicts caused, especially at crossroads. The purpose of this study is to determine the time of departure of vehicles and the base saturation flows at the signalized intersection approach along this road section. This study uses primary and secondary data. Primary data used in the form of intersection geometric data, phase and duration of the signal, and traffic flow data. Whereas the secondary data used is in the form of population and road network map. The departure time is known by using a simple statistical analysis in the form of an average calculation of all cycles of each approach, while the basic saturated flow is obtained using the time slice method. The results obtained are at no peak hours (06.30-08.30 WIB), the average vehicle in 3 of the 4 approaches depart before the green light is on (faster), whereas at peak hours (10.00-12.00 WIB), the average vehicle at 4 approaches leaving after the green light is on (slower). For the base saturated flow value per meter, at non-peak time (06.30-08.30 WIB) and peak time (10.00-12.00 WIB), all intersection approaches studied have a base saturated flow value per meter greater than the value of the base saturated flow per meter in the MKJI 1997 (600 smp/ hour/m), except at the southern approach of the intersection of Kapten Mulyadi Street - Untung Suropati Street at non peak time (06.30-08.30 WIB), which has a base saturated flow per meter of $538.9202 \mathrm{smp} / \mathrm{hour} / \mathrm{m}$.
\end{abstract}

Keywords : base saturated flow, primary collector, signalized intersection, time slice.

\begin{abstract}
Abstrak
Jalan Kapten Mulyadi merupakan salah satu jalan kolektor primer di kota Solo. Selain menjadi salah satu jalur penghubung keluar masuknya kendaraan dari Sukoharjo dan Wonogiri ke kota Solo, sepanjang ruas jalan ini juga merupakan kawasan perdagangan, sehingga pada saat-saat tertentu kondisi jalan ini terbilang cukup padat. Meningkatnya jumlah pengguna kendaraan juga berpengaruh pada semakin tingginya arus lalu lintas dan juga konflik yang ditimbulkan, khususnya di persimpangan jalan. Tujuan dilakukannya penelitian ini yaitu untuk mengetahui waktu keberangkatan kendaraan dan arus jenuh dasar pada pendekat simpang bersinyal di sepanjang ruas jalan ini. Pada penelitian ini, data yang digunakan meliputi data primer dan sekunder. Data primer yang digunakan berupa data geometrik simpang, fase dan durasi sinyal, serta data arus lalu lintas. Sedangkan untuk data sekunder yang digunakan yaitu berupa jumlah penduduk dan peta jaringan jalan. Waktu keberangkatan diketahui dengan menggunakan analisis statistik sederhana berupa perhitungan rata-rata semua siklus tiap pendekat, sedangkan arus jenuh dasar diperoleh dengan menggunakan metode time slice. Hasil yang diperoleh yaitu pada jam tidak puncak (06.3008.30 WIB), rata-rata kendaraan di 3 dari 4 pendekat berangkat sebelum lampu hijau menyala (lebih cepat), sedangkan pada jam puncak (10.00-12.00 WIB), rata-rata kendaraan di 4 pendekat berangkat setelah lampu hijau menyala (lebih lambat). Untuk arus jenuh dasar, hasil yang diperoleh pada jam tidak puncak (06.30-08.30 WIB) maupun jam puncak (10.00-12.00 WIB), semua pendekat simpang yang diteliti memiliki nilai arus jenuh dasar per meter lebih besar dari nilai arus jenuh dasar per meter yang ada pada MKJI 1997 (600 smp/jam/m), kecuali pada pendekat selatan simpang Jl. Kapten Mulyadi-Jl. Untung Suropati pada jam tidak puncak (06.30-08.30 WIB), yang memiliki nilai arus jenuh dasar per meter lebih kecil yaitu sebesar 538,9202 $\mathrm{smp} / \mathrm{jam} / \mathrm{m}$.
\end{abstract}

Kata Kunci : arus jenuh dasar, kolektor primer, simpang bersinyal, time slice.

\section{PENDAHULUAN}

Jalan Kapten Mulyadi merupakan salah satu jalan kolektor primer di kota Solo. Selain menjadi salah satu jalur penghubung keluar masuknya kendaraan dari Sukoharjo dan Wonogiri ke kota Solo, sepanjang ruas jalan ini juga merupakan kawasan perdagangan, sehingga pada saat-saat tertentu kondisi jalan ini terbilang cukup padat. Meningkatnya jumlah pengguna kendaraan juga berpengaruh pada semakin tingginya arus lalu lintas dan juga konflik yang ditimbulkan, khususnya di persimpangan jalan. 
Suatu simpang yang telah dipasang lampu lalu lintas, maka kendaraan yang melintas di simpang tersebut akan mengalami terjadinya kehilangan waktu awal pada saat akan bergerak, yang disebut sebagai pergeseran waktu keberangkatan kendaraan. Hal inilah yang terjadi juga pada simpang bersinyal di sepanjang ruas jalan Kapten Mulyadi, Solo. Selain itu, pada suatu simpang bersinyal, perilaku dan komposisi kendaraan selalu berubah seiring dengan berjalannya waktu, sehingga berpengaruh terhadap perubahan arus jenuh yang dimiliki suatu simpang bersinyal. Maka dari itu, dilakukanlah penelitian ini untuk mengetahui waktu keberangkatan kendaraan dan besarnya arus jenuh dasar yang terjadi pada suatu pendekat simpang bersinyal di sepanjang ruas jalan Kapten Mulyadi, Solo.

\section{LANDASAN TEORI}

\section{Arus Jenuh}

Arus jenuh (saturated flow) adalah arus keberangkatan maksimum yang dapat dihasilkan dari suatu pendekat persimpangan selama waktu lampu hijau (smp/jam hijau) yang merupakan fungsi dari lebar efektif pendekat persimpangan (Ofyar, 2008). Menurut MKJI 1997, persamaan yang digunakan untuk menghitung besarnya nilai arus jenuh suatu persimpangan adalah sebagai berikut :

$$
\mathrm{S}=\mathrm{S}_{0} \times \mathrm{FCS}_{\mathrm{C}} \times \mathrm{FSF}_{\mathrm{SF}} \times \mathrm{F}_{\mathrm{G}} \times \mathrm{FP}_{\mathrm{P}} \times \mathrm{F}_{\mathrm{RT}} \times \mathrm{F}_{\mathrm{LT}}
$$

\section{Arus Jenuh Dasar}

Menurut MKJI 1997, arus jenuh dasar didefinisikan sebagai besarnya keberangkatan antrian di dalam pendekat simpang selama kondisi ideal (smp/jam hijau). Menurut MKJI 1997, nilai arus jenuh dasar pada pendekat dengan tipe arus terlindung dapat dihitung dengan menggunakan rumus sebagai berikut:

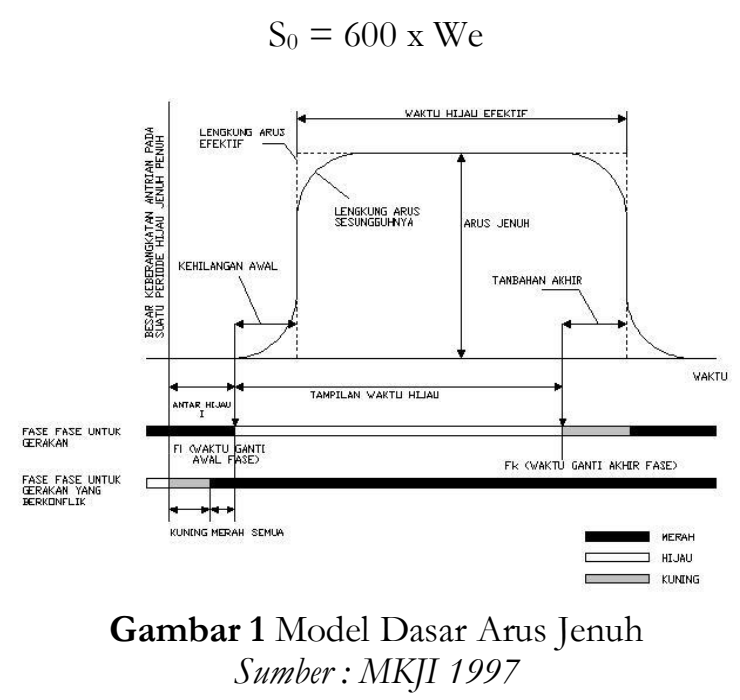

\section{Metode Time Slice}

Metode ini digunakan untuk menganalisis arus jenuh dengan membagi arus lalu lintas ke dalam beberapa potongan waktu (time-slice) pada setiap siklus lampu hijau. Alokasi waktu untuk setiap potongan slice yang ditentukan pada penelitian ini yaitu sebesar 6 detik dengan jumlah interval tiap slice yang memenuhi syarat saturation flow paling sedikit 20 interval waktu hijau. Menurut MKJI 1997, rumus yang digunakan untuk melakukan perhitungan nilai emp pada masing-masing potongan waktu adalah sebagai berikut :

$$
(\Sigma \mathrm{Lv} \times \mathrm{emp} \mathrm{Lv}+\Sigma \mathrm{Hv} \times \mathrm{empHv}+\Sigma \mathrm{Lv} \times \mathrm{emp} \mathrm{Lv}) \times \frac{3600}{\mathrm{t}}=\mathrm{S}
$$

\section{Waktu Keberangkatan Kendaraan}

Waktu keberangkatan kendaraan didefinisikan sebagai selisih waktu yang dibutuhkan oleh kendaraan pertama pada suatu pendekat simpang bersinyal untuk mulai bergerak melewati stopline dengan saat lampu hijau mulai menyala. Untuk mengetahui rata-rata waktu keberangkatan kendaraan tiap pendekat simpang bersinyal yaitu dengan cara menjumlahkan semua waktu keberangkatan kendaraan tiap siklus kemudian dibagi dengan jumlah siklus :

$$
\bar{x}=\frac{1}{n} \sum_{i=1}^{n} x_{i}
$$


Nilai $\bar{x}$ merupakan simbol dari nilai rata-rata waktu keberangkatan kendaraan yang digunakan untuk mengetahui rata-rata waktu keberangkatan kendaraan tiap pendekat simpang bersinyal yang diteliti selama jam tidak puncak (06.30-08.30 WIB) maupun jam puncak (10.00-12.00 WIB).

\section{METODE}

Pada penelitian ini, rata-rata waktu keberangkatan kendaraan tiap pendekat simpang bersinyal diperoleh dengan membagi jumlah waktu keberangkatan kendaraan semua siklus dengan jumlah siklusnya. Langkah pertama yang dilakukan yaitu mengamati kendaraan pertama yang bergerak melewati stopline pada saat lampu hijau mulai menyala tiap siklus dan mencatat selisih waktunya. Setelah itu, selisih waktu yang diperoleh tiap siklus dijumlahkan lalu dibagi dengan jumlah siklus selama penelitian. Hasil yang diperoleh yaitu berupa rata-rata waktu keberangkatan kendaraan tiap pendekat simpang yang diteliti pada saat jam tidak puncak maupun jam puncak.

Kemudian untuk menganalisis arus jenuh dasar yaitu dengan menggunakan metode time slice. Data yang digunakan terdiri dari data primer dan data sekunder. Data primer yang digunakan berupa data geometrik simpang, fase sinyal, durasi sinyal, dan data arus lalu lintas, sedangkan data sekunder yang digunakan berupa data jumlah penduduk dan juga peta jaringan jalan kota Solo. Langkah pertama yang dilakukan yaitu mengumpulkan data primer dengan cara survei langsung di lapangan dan data sekunder dengan mengambil di internet. Langkah kedua yaitu mengkalibrasikan satuan tiap jenis kendaraan pada data arus lalu lintas yang didapat dengan ekivalensi mobil penumpang sehingga menjadi satuan mobil penumpang. Langkah selanjutnya yaitu membagi waktu lampu hijau tiap siklus ke dalam beberapa potongan waktu (time-slice)/ interval dimana tiap potongannya ditentukan sebesar 6 detik. Kemudian menghitung jumlah kendaraan (yang sudah diubah satuannya menjadi smp) tiap intervalnya. Langkah selanjutnya yaitu menghitung nilai arus jenuh tiap interval dengan cara membagi jumlah kendaraan (smp) dengan jumlah siklus. Setelah didapatkan nilai arus jenuh tiap interval, kemudian menghitung nilai arus jenuh keseluruhan dengan cara merata-rata hasil arus jenuh tiap intervalnya. Setelah diketahui nilai arus jenuh (S), langkah selanjutnya yaitu menghitung nilai arus jenuh dasar $\left(\mathrm{S}_{0}\right)$ dengan cara membagi nilai arus jenuh $(\mathrm{S})$ dengan faktor penyesuain yang ada pada tiap pendekat. Nilai faktor penyesuaian ini dipengaruhi oleh jumlah populasi kota, geometrik simpang berupa kelandaian, hambatan samping, kendaraan parkir, serta rasio arus belok kanan dan belok kiri. Langkah terakhir yaitu menghitung besarnya nilai arus jenuh dasar per meter $\left(\mathrm{S}_{0} / \mathrm{m}\right)$ dengan cara membagi nilai arus jenuh dasar $\left(\mathrm{S}_{0}\right)$ yang diperoleh dengan lebar efektif pendekat.

\section{HASIL DAN PEMBAHASAN}

Berdasarkan penelitian di tiap pendekat simpang bersinyal yang diteliti, diperoleh hasil rata-rata selisih waktu keberangkatan kendaraan dan arus jenuh dasar per meter $\left(\mathrm{S}_{0} / \mathrm{m}\right)$ seperti yang ditampilkan pada Tabel 1 - Tabel 2 .

Tabel 1 Waktu Keberangkatan Kendaraan Tiap Simpang pada Jam Tidak Puncak (06.30-08.30 WIB)

\begin{tabular}{ccccc}
\hline \multirow{2}{*}{$\begin{array}{c}\text { Waktu } \\
\text { Keberangkatan } \\
\text { (detik) }\end{array}$} & $\begin{array}{c}\text { Simpang J1. Kapten Mul- } \\
\text { yadi - J1. Mayor Sunaryo } \\
\text { dan J1. Demangan }\end{array}$ & $\begin{array}{c}\text { Simpang J1. Kapten Mulyadi - J1. Un- } \\
\text { tung Suropati }\end{array}$ & $\begin{array}{c}\text { Simpang J1. Kapten } \\
\text { Mulyadi - J1. Veteran } \\
\text { dan J1. Kyai Mojo }\end{array}$ \\
\cline { 2 - 5 } & Pendekat Utara & Pendekat Utara & Pendekat Selatan & Pendekat Utara \\
\hline-2 & 1 & 5 & 13 & 9 \\
-1 & 17 & 25 & 35 & 27 \\
0 & 34 & 30 & 16 & 20 \\
1 & 25 & 11 & 10 & 12 \\
2 & 3 & 4 & 1 & 2 \\
\hline \hline Rata-rata Waktu & 0,15 detik & $-0,2133$ detik & $-0,6533$ detik & $-0,4143$ detik \\
Keberangkatan & & & &
\end{tabular}

Tabel 2 Waktu Keberangkatan Kendaraan Tiap Simpang pada Jam Puncak (10.00-12.00 WIB)

\begin{tabular}{ccccc}
\hline \multirow{2}{*}{$\begin{array}{c}\text { Waktu } \\
\text { Keberangkatan } \\
\text { (detik) }\end{array}$} & $\begin{array}{c}\text { Simpang J1. Kapten Mul- } \\
\text { yadi - Jl. Mayor Sunaryo } \\
\text { dan J1. Demangan }\end{array}$ & $\begin{array}{c}\text { Simpang J1. Kapten Mulyadi - J1. Un- } \\
\text { tung Suropati }\end{array}$ & $\begin{array}{c}\text { Simpang J1. Kapten } \\
\text { Mulyadi - Jl. Veteran } \\
\text { dan J1. Kyai Mojo }\end{array}$ \\
\cline { 2 - 5 } & Pendekat Utara & Pendekat Utara & Pendekat Selatan & Pendekat Utara \\
\hline-2 & 1 & 1 & 2 & 3 \\
-1 & 17 & 10 & 5 & 14 \\
0 & 12 & 11 & 19 & 10 \\
\hline
\end{tabular}




\begin{tabular}{ccccccccc}
\hline $0.0-6.0$ & 1124 & 89 & 5 & 1218 & 224,8 & 89 & 6,5 & 320,3 \\
$6.1-12.0$ & 970 & 143 & 4 & 1117 & 194 & 143 & 5,2 & 342,2 \\
$12.1-18.0$ & 710 & 141 & 4 & 855 & 142 & 141 & 5,2 & 288,2 \\
$18.1-24.0$ & 572 & 90 & 4 & 666 & 114,4 & 90 & 5,2 & 209,6 \\
\hline
\end{tabular}

Tabel 8 Data Arus Lalu Lintas di Pendekat Selatan Jl. Kapten Mulyadi - Jl. Untung Suropati pada Jam Puncak (10.00-12.00 WIB)

\begin{tabular}{ccccccccc}
\hline $\begin{array}{c}\text { Interval } \\
\text { (detik) }\end{array}$ & \multicolumn{4}{c}{ Arus Lalu Lintas (kend.) } & \multicolumn{3}{c}{ Arus Lalu Lintas (smp) } \\
\cline { 2 - 9 } & MC & LV & HV & $\sum$ & MC & LV & HV & $\Sigma$ \\
\hline $0.0-6.0$ & 848 & 166 & 8 & 1022 & 169,6 & 166 & 10,4 & 346 \\
$6.1-12.0$ & 628 & 225 & 6 & 859 & 125,6 & 225 & 7,8 & 358,4 \\
$12.1-18.0$ & 677 & 196 & 5 & 878 & 135,4 & 196 & 6,5 & 337,9 \\
$18.1-24.0$ & 543 & 160 & 5 & 708 & 108,6 & 160 & 6,5 & 275,1 \\
\hline
\end{tabular}

Tabel 9 Data Arus Lalu Lintas di Pendekat Utara Jl. Kapten Mulyadi - Jl. Veteran dan Jl. Kyai Mojo pada Jam Tidak Puncak (06.30-08.30 WIB)

\begin{tabular}{ccccccccc}
\hline Interval & \multicolumn{4}{c}{ Arus Lalu Lintas (kend.) } & \multicolumn{5}{c}{ Arus Lalu Lintas (smp) } \\
\cline { 2 - 9 } (detik) & MC & LV & HV & $\Sigma$ & MC & LV & HV & $\Sigma$ \\
\hline $0.0-6.0$ & 1149 & 61 & 8 & 1218 & 229,8 & 61 & 10,4 & 301,2 \\
$6.1-12.0$ & 921 & 133 & 9 & 1053 & 184,2 & 123 & 11,7 & 318,9 \\
$12.1-18.0$ & 371 & 133 & 8 & 512 & 74,2 & 133 & 10,4 & 217,6 \\
$18.1-24.0$ & 181 & 83 & 10 & 274 & 36,2 & 83 & 13 & 132,2 \\
$24.1-30.0$ & 147 & 17 & 3 & 167 & 29,4 & 17 & 3,9 & 50,3 \\
\hline
\end{tabular}

Tabel 10 Data Arus Lalu Lintas di Pendekat Utara Jl. Kapten Mulyadi - Jl. Veteran dan Jl. Kyai Mojo pada Jam Puncak (10.00-12.00 WIB)

\begin{tabular}{|c|c|c|c|c|c|c|c|c|}
\hline \multirow{2}{*}{$\begin{array}{c}\begin{array}{c}\text { Interval } \\
\text { (detik) }\end{array}\end{array}$} & \multicolumn{4}{|c|}{ Arus Lalu Lintas (kend.) } & \multicolumn{4}{|c|}{ Arus Lalu Lintas (smp) } \\
\hline & $\mathrm{MC}$ & LV & HV & $\Sigma$ & $\mathrm{MC}$ & LV & $\mathrm{HV}$ & $\Sigma$ \\
\hline $0.0-6.0$ & 825 & 192 & 7 & 1024 & 165 & 192 & 9,1 & 366,1 \\
\hline $6.1-12.0$ & 674 & 202 & 14 & 890 & 134,8 & 202 & 18,2 & 355 \\
\hline $12.1-18.0$ & 402 & 198 & 13 & 613 & 80,4 & 198 & 16,9 & 295,3 \\
\hline $18.1-24.0$ & 291 & 169 & 10 & 470 & 58,2 & 169 & 13 & 240,2 \\
\hline
\end{tabular}

Berdasarkan perhitungan menggunakan metode time slice, diperoleh besarnya nilai arus jenuh, arus jenuh dasar, dan arus jenuh dasar per meter pada tiap pendekat simpang bersinyal yang diteliti selama jam tidak puncak (06.30-08.30 WIB) dan jam puncak (10.00-12.00 WIB) yang dapat dilihat pada Tabel 11 - Tabel 12 berikut.

Tabel 11 Arus Jenuh, Arus Jenuh Dasar, dan Arus Jenuh Dasar Per Meter Tiap Simpang pada Jam Tidak Puncak (06.30-08.30 WIB)

\begin{tabular}{ccccc}
\hline Simpang & Pendekat & $\begin{array}{c}\text { Arus Jenuh } \\
\text { (Smp/jam) }\end{array}$ & $\begin{array}{c}\text { Arus Jenuh Dasar } \\
\text { (Smp/jam) }\end{array}$ & $\begin{array}{c}\text { Arus Jenuh Dasar Per Meter } \\
\text { (Smp/jam/m) }\end{array}$ \\
\hline $\begin{array}{c}\text { Jl. Kapten Mulyadi-Jl. Mayor } \\
\text { Sunaryo dan Jl. Demangan }\end{array}$ & Utara & 1757,2500 & 1977 & 696,2421 \\
Jl. Kapten Mulyadi - Jl. Untung & Utara & 1842,7200 & 2087 & 624,9024 \\
$\begin{array}{c}\text { Suropati } \\
\text { J1. Kapten Mulyadi - Jl. Veteran dan } \\
\text { Jl. Kyai Mojo }\end{array}$ & Selatan & 2320,6000 & 2695 & 538,9202 \\
& Utara & 1748,9143 & 2168 & 763,3879 \\
\hline
\end{tabular}

Tabel 12 Arus Jenuh, Arus Jenuh Dasar, dan Arus Jenuh Dasar Per Meter Tiap Simpang pada Jam Puncak (10.00$12.00 \mathrm{WIB})$

\begin{tabular}{ccccc}
\hline Simpang & Pendekat & $\begin{array}{c}\text { Arus Jenuh } \\
\text { (Smp/jam) }\end{array}$ & $\begin{array}{c}\text { Arus Jenuh Dasar } \\
\text { (Smp/jam) }\end{array}$ & $\begin{array}{c}\text { Arus Jenuh Dasar Per Meter } \\
\text { (Smp/jam/m) }\end{array}$ \\
\hline $\begin{array}{c}\text { Jl. Kapten Mulyadi - Jl. Mayor } \\
\text { Sunaryo dan Jl. Demangan }\end{array}$ & Utara & 2040,1500 & 2324 \\
& Utara & 2123,6667 & 2441 \\
& & & 730,8652 \\
\hline
\end{tabular}


Untuk arus jenuh dasar per meter $\left(\mathrm{S}_{0} / \mathrm{m}\right)$, pada jam puncak maupun tidak puncak, hampir semua pendekat simpang memiliki nilai arus jenuh dasar per meter $\left(\mathrm{S}_{0} / \mathrm{m}\right)$ melebihi standar MKJI 1997 (600 smp/jam/m), kecuali yang terdapat pada pendekat selatan simpang Jl. Kapten Mulyadi - Jl. Untung Suropati pada jam tidak puncak. Seperti yang telah dijelaskan dalam metode yang dilakukan, nilai arus jenuh dasar per meter diperoleh dari hasil bagi antara arus jenuh dasar dengan lebar efektif pendekatnya.

Hubungan antara rata-rata waktu keberangkatan dengan arus jenuh dan arus jenuh dasar per meter, serta hubungan antara arus jenuh dasar per meter dengan lebar pendekat keluar pada jam tidak puncak (06.30-08.30 WIB) dan jam puncak (10.00-12.00 WIB) dapat dilihat pada Gambar 2 - Gambar 7.

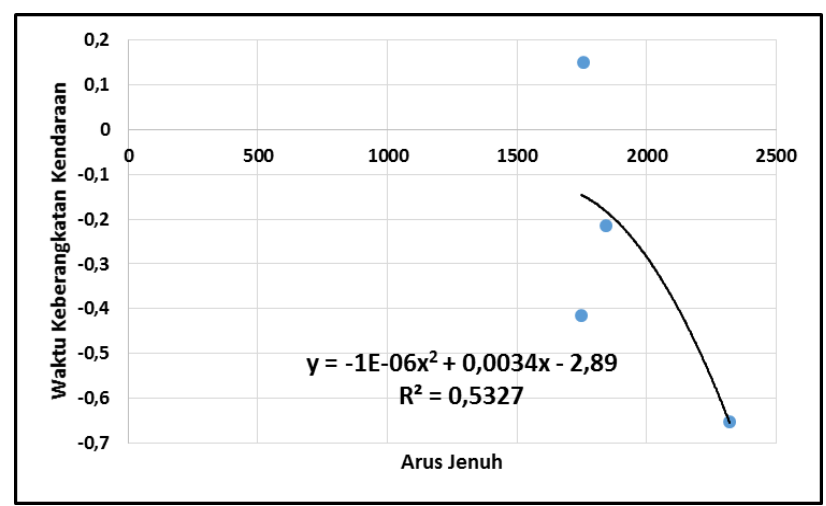

Gambar 2 Grafik Hubungan Arus Jenuh dengan Rata-rata Waktu Keberangkatan Kendaraan pada Jam Tidak Puncak

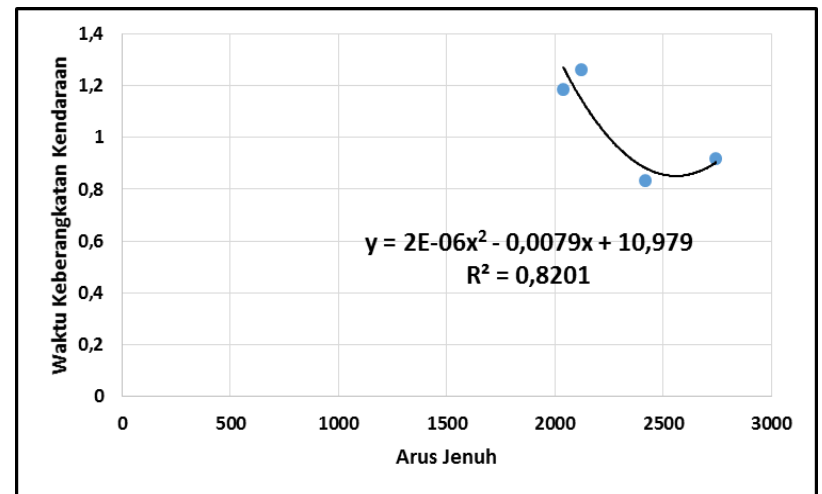

Gambar 3 Grafik Hubungan Arus Jenuh dengan Rata-rata Waktu Keberangkatan Kendaraan pada Jam Puncak

Berdasarkan grafik pada Gambar 2 dan Gambar 3 di atas, dapat dilihat bahwa pada jam tidak puncak (06.30-08.30 WIB), sebesar 53,27\% faktor yang mempengaruhi terjadinya pergeseran waktu keberangkatan kendaraan adalah arus jenuh dan 46,73\% sisanya adalah disebabkan oleh faktor lain. Sedangkan pada jam puncak (10.00-12.00 WIB), sebesar $82,01 \%$ faktor yang mempengaruhi terjadinya pergeseran waktu keberangkatan kendaraan adalah arus jenuh dan $17,99 \%$ sisanya adalah disebabkan oleh faktor lain. 


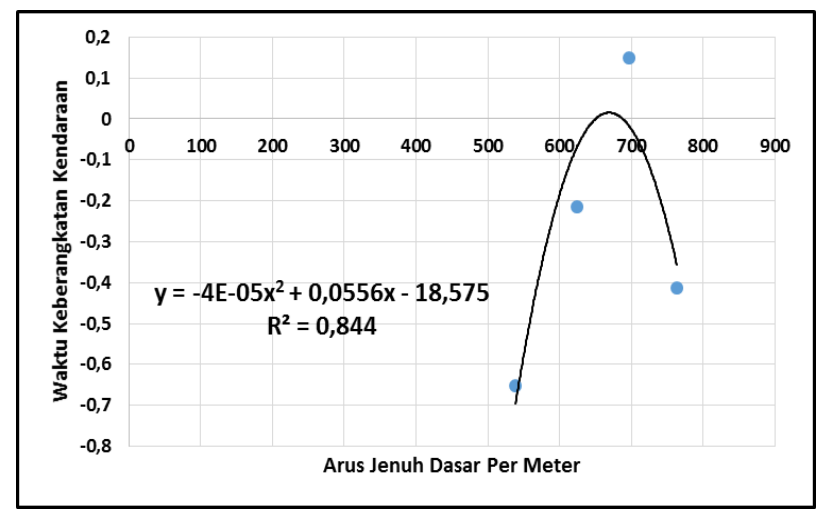

Gambar 4 Grafik Hubungan antara Arus Jenuh Dasar Per Meter dengan Rata-rata Waktu Keberangkatan Kendaraan pada Jam Tidak Puncak

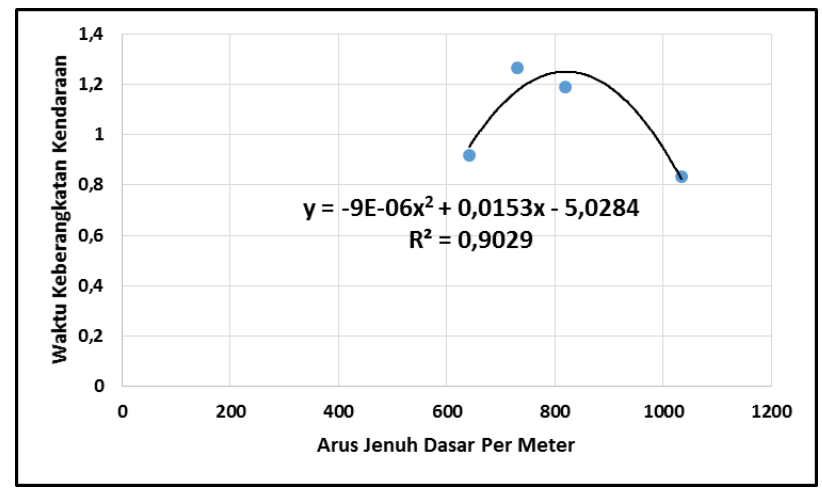

Gambar 5 Grafik Hubungan antara Arus Jenuh Dasar Per Meter dengan Rata-rata Waktu Keberangkatan Kendaraan pada Jam Puncak

Berdasarkan grafik pada Gambar 4 dan Gambar 5 di atas, dapat dilihat bahwa pada jam tidak puncak (06.30-08.30 WIB), sebesar $84,40 \%$ faktor yang mempengaruhi terjadinya pergeseran waktu keberangkatan kendaraan adalah arus jenuh dasar per meter dan 15,6\% sisanya adalah disebabkan oleh faktor lain. Sedangkan pada jam puncak (10.00-12.00 WIB), sebesar 90,29\% faktor yang mempengaruhi terjadinya pergeseran waktu keberangkatan kendaraan adalah arus jenuh dasar per meter dan $9,71 \%$ sisanya adalah disebabkan oleh faktor lain.

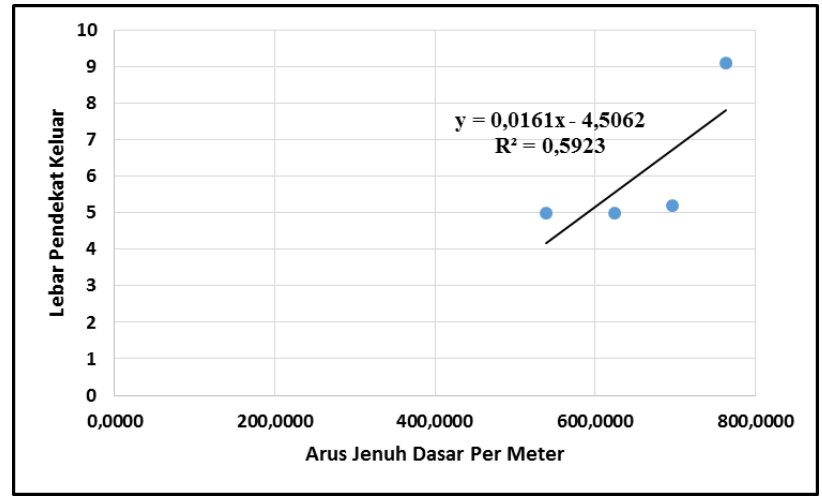

Gambar 6 Grafik Hubungan antara Arus Jenuh Dasar Per Meter pada Jam Tidak Puncak dengan Lebar Pendekat Keluar 


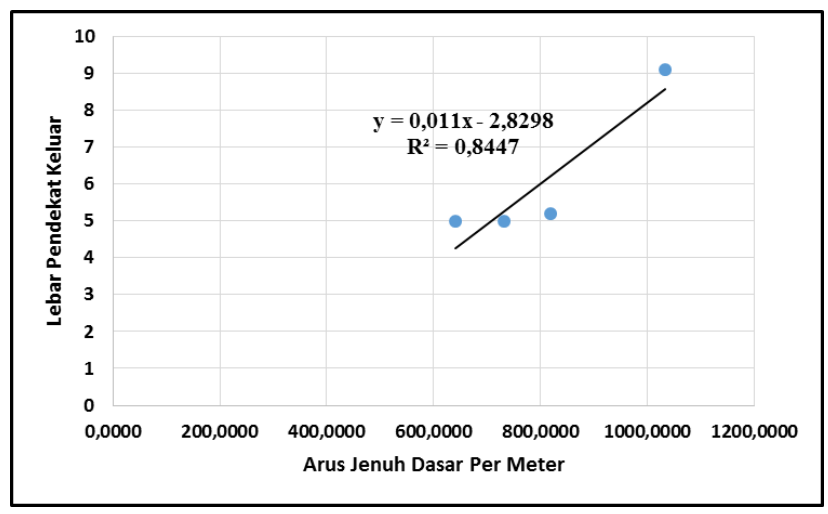

Gambar 7 Grafik Hubungan antara Arus Jenuh Dasar Per Meter pada Jam Puncak dengan Lebar Pendekat Keluar

Berdasarkan grafik pada Gambar 6 dan Gambar 7 di atas, dapat dilihat bahwa pada jam tidak puncak (06.30-08.30 WIB), sebesar 59,23\% faktor yang mempengaruhi arus jenuh dasar per meter adalah lebar pendekat keluar dan 40,77\% sisanya adalah disebabkan oleh faktor lain. Sedangkan pada jam puncak (10.00-12.00 WIB), sebesar 84,47\% faktor yang mempengaruhi arus jenuh dasar per meter adalah lebar pendekat keluar dan 15,53\% sisanya adalah disebabkan oleh faktor lain.

\section{KESIMPULAN}

Pada jam tidak puncak (06.30-08.30 WIB), rata-rata kendaraan di semua pendekat cenderung mulai bergerak melewati stopline sebelum sinyal hijau menyala. Sedangkan pada jam puncak (10.0-12.00 WIB), kendaraan di semua pendekat mulai bergerak melewati stopline setelah sinyal hijau menyala. Untuk arus jenuh dasar per meter yang didapatkan, baik pada jam tidak puncak (06.30-08.30 WIB) maupun jam puncak (10.00-12.00 WIB), semua pendekat pada simpang yang diteliti memiliki nilai arus jenuh dasar per meter melebihi MKJI 1997 (600 $\mathrm{smp} / \mathrm{jam} / \mathrm{m}$ ), kecuali pada pendekat selatan simpang Jl. Kapten Mulyadi - Jl. Untung Suropati dan itu terjadi pada jam tidak puncak yaitu sebesar 538,9202 smp/jam/m.

\section{UCAPAN TERIMAKASIH}

Ucapan terima kasih penyusun ucapkan kepada yang terhormat Ibu Amirotul Musthofiah HM, S.T.,M.Sc. dan Bapak S. J. Legowo, S.T., M.T., selaku Dosen Pembimbing skripsi yang telah meluangkan waktu, pikiran, dan tenaga untuk membimbing penyusun dengan penuh kesabaran, sehingga skripsi ini bisa terselesaikan dengan baik. Penyusun juga mengucapkan terimakasih kepada seluruh pihak, yang baik secara langsung maupun tidak langsung telah membantu penyusun dalam menyelesaikan laporan skripsi ini.

\section{REFERENSI}

1997. Manual Kapasitas Jalan Indonesia (MKJI). Departemen Pekerjaan Umum Direktorat Jenderal Bina Marga.

Bowoputro, Hendi, M.Zainul Arifin, Lutfi Djakfar, dan Rahayu Kusumaningrum. 2014. Kajian Arus Jenuh Pada Simpang Bersinyal di Kota Malang Bagian Selatan. Jurnal Rekayasa Sipil Volume 8, No.2 - 2014 ISSN 1978 -5658 .

Dwipayana, A.A. Gde Ngurah Cakra. 2016. Perbandingan Kinerja Simpang Bersinyal Yang Menggunakan Countdown Timer Dengan Metode Time Slice Dan Mkji Pada Simpang Bersinyal Jalan Raya Padang Luwih

- Dalung Permai. Undergraduate thesis, Universitas Warmadewa.

Hamad, Khaled, and Hassan Abuhamda. 2015. Estimating Base Saturation Flow Rate for Selected Signalized Intersections in Doha, Qatar. Journal of Traffic and Logistics Engineering Vol. 3, No. 2, December 2015.

Jonathan, Sarwono. 2006. Metode Penelitian Kuantitatif dan Kualitatif. Graha Ilmu. Yogyakarta

https://exponensial.wordpress.com/2009/06/24/deviasi-kuartil/

https://rumus-rumus.com/standar-deviasi/

Panjaitan, Tri Utamy Yohana. 2018. Studi Variasi Waktu Keberangkatan Lalu Lintas dan Perbandingan Arus Jenuh Dasar Metode Time Slice dengan Arus Jenuh Dasar MKJI 1997 Pada Simpang Bersinyal dengan Short Time Countdown Timer. Program Studi Teknik Sipil Fakultas Teknik. Universitas Sebelas Maret Surakarta.

Pratina, Ginung. 2018. Analisis Pergeseran Waktu Keberangkatan Kendaraan Dan Arus Jenuh Pada Simpang Bersinyal Yang Dilengkapi Dengan Full Time Countdown Timer. Program Studi Teknik Sipil Fakultas Teknik. Universitas Sebelas Maret Surakarta. 
Prasetyowati, Dindin Astriani. 2016. Analisa Statistik (Teori Dan Aplikasi Menggunakan Spss). Fakultas Ilmu Komputer. Universitas Indo Global Mandiri. Palembang. 